\title{
BIODIVERSIDADE: ENREDAMENTO DENTRO DE UMA LÓGICA INTERDISCIPLINAR, OLHARES E ESTRANHAMENTOS
}

\author{
Luiz Ernani Bonesso de Araújo', Tanny Oliveira Lima Bohner², \\ Juliana Cezimbra²; Liliane Costa de Barros²; \\ ${ }^{1}$ Professor do Curso de especialização em Educação Ambiental, Universidade Federal de Santa Maria, RS, Brasil. E- \\ mail: luiz.bonesso@gmail.com \\ ${ }^{2}$ Enghenheira Florestal, aluna do programa de especialização em Educação Ambiental pela Universidade Federal de \\ Santa Maria - UFSM. E-mail: tanny.bohner@hotmail.com \\ ${ }^{3}$ Graduada em Educação Especial, aluna do programa de especialização em Educação Ambiental pela Universidade \\ Federal de Santa Maria - UFSM. E-mail: jucezimbra@bol.com.br \\ ${ }^{4}$ Bióloga, aluna do programa de especialização em Educação Ambiental pela Universidade Federal de Santa Maria - \\ UFSM. E-mail: lilianecbarros@hotmail.com
}

\section{RESUMO}

A partir de um olhar que trata a educação ambiental com uma percepção interdisciplinar, com um sentido transformador, no presente trabalho busca-se realizar uma análise acerca do termo biodiversidade, bem como dos debates que o norteiam. A abordagem feita durante o trabalho teve o objetivo de problematizar o papel social que esse termo vem assumindo nos dias atuais, visto que muitas vezes o emprego desse termo tem assumido outros papéis que não o seu real. Tem-se como conclusão a importância da educação ambiental como ferramenta fundamental para ser utilizada em programas que visem conscientizar as pessoas sobre a conservação da biodiversidade, explicitando a relação direta que este desafio proposto tem com as características da sociedade moderna e época pós-moderna em que vivemos.

Palavras-chave: Biodiversidade, educação ambiental, pós-modernidade, sustentabilidade.

\section{ABSTRACT}

The present study attempts to perform an analysis on the term biodiversity through an environmental education perspective, concerning an interdisciplinary awareness, as well as a transformer sense. The approach taken during the study aimed to discuss the social role that this term has taken nowadays, whereas most of the times its use has taken other roles rather than the real one. It is concluded that the environmental education is a fundamental tool to develop an environmental consciousness, highlighting the direct relation among the proposed challenge, the modern society and the biodiversity conservation. 


\section{REGETUFSM}

Rev. Elet. em Gestão, Educação e Tecnologia Ambiental

(e-ISSN: 2236-1170)

Keywords: biodiversity, environmental education, post-modernity, sustainability.

\section{INTRODUÇÃO}

Pensar a educação ambiental a partir de uma percepção interdisciplinar é partir do pressuposto que essa tenha um sentido transformador, ou seja, de construir um lugar diferenciado para se pensar essa prática. Trazer a interdisciplinaridade como linha norteadora parte não é somente trabalhar entre disciplina, mas é organizar um trabalho, com uma equipe que tenha cooperação e principalmente que esteja preparada para pesquisar e "abrir " seu olhar para outra especificidade.

A partir desse olhar sobre um assunto que não pode mais ser tratado como único disciplinar, é que se entende que a educação ambiental perpassa esses limites de uni disciplinar SOARES (1999). Em conjunto com esta separação, temos aquela expressa na unidisciplinaridade, ou, "hiperespecialização", a qual impede uma visão interacional do que existe nas distintas áreas do conhecimento, e esgota-se como modelo explicativo do homem e de suas relações sociais" A educação ambiental deve estar conectada com o paradigma da interdisciplinaridade que nos permite sair da perspectiva do individual, do especialista, ou seja, busca-se sempre as relações entre as disciplinas.

É nesse momento que falar em educação ambiental se torna pertinente dentro de uma sociedade que está se caracterizando como moderna, e que atualmente vive em uma condição pós moderna onde as relações de poder estão explicitas, sem mascaras, ou escondidas por trás de alguma coisa, todos somos seres governáveis e autogovernados e nossa vida é permeada por relações de poder. Ao afirmar que "em qualquer sociedade, o corpo está preso no interior de poderes muito apertados, que the impõem limitações, proibições ou obrigações" (FOUCAULT, 2004, p. 126), Foucault já explicita que essas relações afetam toda a sociedade, acarretando em transformações e modificações de condutas nos indivíduos, nos tornando maleáveis e "dóceis". 0 corpo social, ao longo dos séculos, se consolida como algo fabricado, influenciado por um currículo, pois O currículo é formador de identidade e mecanismo de modelagem, ou seja, um currículo pode moldar a maneira com que queremos que as coisas funcionem. VEIGA-NETO (2001, p. 235), diz que o currículo funcionou (e funciona) como um importante artefato envolvido nos processos de controle em geral (e dominação) e de subjetivação. 


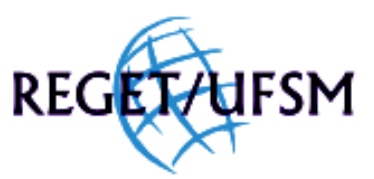

Araújo et al., v(6), no 6, p. 1203 - 1210, 2012.

Nesse contexto, abordaremos nesse trabalho a visão de biodiversidade dentro do paradigma da interdisciplinaridade, onde nos cabe problematizar o papel social que esse termo vem assumindo nos dias de hoje, visto que muitas vezes o emprego desse termo tem assumido outros papéis que não o seu real. Sabemos que estudar a biodiversidade não é um atarefa fácil, pois estamos falando de toda a diversidade da natureza, e é nesse espaço que queremos com esse texto problematizar as questões que tem rodeado e enredado este tema.

\section{Definição do conceito de Biodiversidade}

O termo biodiversidade (do grego bios=vida) significa a diversidade da natureza viva. A partir de 1986 o termo passou a ser muito utilizado pelos biólogos, lideres políticos (entre outros) a fim de conscientizar toda a população sobre esse tema. No entanto, esse assunto coincidiu com a grande preocupação com a diminuição da variedade genética (populações e espécies), variedade de espécies (flora e fauna), fungos (macro e microrganismos), entre outros. De acordo o Artigo 2 da Conservação Sobre Diversidade Biológica,

[...] pode ser entendido como a variabilidade dos organismos vivos de todas as origens, abrangendo os ecossistemas terrestres, marinhos, e outros ecossistemas aquáticos, incluindo seus complexos; e compreendendo a diversidade dentro de espécies, entre espécies e de ecossistemas. (Brasil, 2002)

A biodiversidade inclui a totalidade dos recursos genéticos, vivos, biológicos e seus componentes, ou seja, refere-se ao número de riqueza dos diferentes conjuntos biológicos e a abundância relativa destas categorias. Compreende também a variabilidade ao nível local e entre paisagens, complementariedade biológica (entre habitats). 


\begin{tabular}{|c|c|c|}
\hline \multicolumn{3}{|l|}{ Espedes biologieas da Terra } \\
\hline Forma de vida & $\begin{array}{l}\text { Espedies } \\
\text { conhedidas }\end{array}$ & Espécies totais estimadas \\
\hline Insetos e outros artrópodes & 874.161 & 30 milhões. \\
\hline Plantas altas & 248.400 & $\begin{array}{l}\text { Variam de } 275 \text { mil a mais de } 400 \text { mil. } \\
\text { Acredita-se que, no mínimo, de } 10 \% \\
\text { a } 15 \% \text { de todas as plantas ainda năo } \\
\text { foram descobertas. }\end{array}$ \\
\hline Invertebrados & 116.873 & Podem chegar a milhǒes. \\
\hline Plantas baixas & 73.900 & Nâo disponível. \\
\hline Microorganismos & 36.600 & Nầ disponivel. \\
\hline Peixes & 19.056 & $\begin{array}{l}21.000 \text {, assumindo que } 10 \% \text { dos } \\
\text { peixes ainda năo săo conhecidos. }\end{array}$ \\
\hline Pássaros & 9.040 & $\begin{array}{l}\text { Estima-se que as espécies } \\
\text { conhecidas respondam por } \\
\mathbf{9 8} \% \text { de todos os pássaros. }\end{array}$ \\
\hline Mamíferos & 4.000 & $95 \%$ das espécies já săo conhecidas. \\
\hline Répteis e anfibios & 8.692 & $95 \%$ das espécies já são conhecidas. \\
\hline Total & 1.390 .992 & Pode exceder a $\mathbf{3 0}$ milhŏes. \\
\hline
\end{tabular}

Fonte: IBGE, 2011.

De acordo com o Prof. Carlos Daniel Pérez, em 1980, Thomas Lovejoy criou o termo "biodiversidade", mas o termo foi usado (pela primeira vez) por E. O Wilson, ao apresentar um relatório no Fórum Americano sobre a diversidade, organizado pelo National Research Council. A palavra "biodiversidade" foi indicada para substituir "diversidade biológica", pois essa expressão era considerada pouco eficaz em termos de comunicação.

Não há um significado consensual de Biodiversidade. Um conceito é: "avaliação da diversidade referente entre organismos presentes em diversos ecossistemas". Neste sentido, abarca a diversidade dentro da espécie, entre espécies e diversidade comparativa entre ecossistemas.

Outra definição aponta que é um "conjunto dos genes, espécies e ecossistemas de uma região". Este sentido integra os três níveis habituais de diversidade entre seres vivos:

- diversidade genética - diversidade dos genes em uma espécie.

- diversidade de espécies - diversidade entre espécies.

- diversidade de ecossistemas - diversidade em um nível mais alto de organização, incluindo todos os níveis de variação desde o genético. 
REGEX广AFSM

Araújo et al., v(6), № 6, p. $1203-1210,2012$.

1207

Rev. Elet. em Gestão, Educação e Tecnologia Ambiental

(e-ISSN: 2236-1170)

O enfoque foi expandido a partir da Conferencia Mundial sobre Meio Ambiente e Desenvolvimento (CNUMAD ou Rio-92), que reuniu representantes de governos e povos de centenas de nações, consolidando a Convenção da Diversidade Biológica (CDB), marco fundamental para debater este tema. É reconhecido que o conceito de diversidade biológica ou biodiversidade varia dependendo do setor onde é empregado, contudo de acordo com a CDB, tem sucessivamente evidência na variabilidade de organismos vivos de todas as origens, envolvendo, entre outros, os ecossistemas (terrestres, marinhos e aquáticos), e os complexos ecológicos de que fazem parte. Envolve ainda a diversidade dentro e entre espécies e de ecossistemas.

Ao trabalhar com uma visão unificada de distintos elementos constituintes da natureza, tendo em vista a conservação de princípios operacionais e bem estar de populações, devem-se ponderar processos que incluam, simultaneamente, exame e estimativa de aspectos ambientais, procedimentos de produção, e aspectos socioeconômico-culturais. O estudo que aborda esta interconexão é uma extensão da ciência que, durante longo tempo, foi vista num significado bastante limitado, como assunto ligado apenas à institutos "ecologistas".

O progresso da tomada de consciência em relação ao meio ambiente aumentou a discussão, mostrando uma nova visão sobre os recursos biológicos. Destaca-se que, dependendo dos setores envolvidos na discussão, a biodiversidade é entendida como um fator fundamental para a própria sobrevivência humana, integrando, neste conjunto, o homem, como um de seus elementos.

O ser humano sempre utilizou os recursos naturais em prol de seu desenvolvimento e mesmo para sua subsistência, mas a explosão demográfica e o desenvolvimento tecnológico das últimas décadas aumentaram sensivelmente chegando a comprometer muitos dos ecossistemas da terra.

Segundo Varella e Rocha (1999), os sistemas agrícolas são ecossistemas manejados. Embora o manejo feito pelo homem tenha frequentemente modificado ecossistemas naturais de forma substancial, as atividades agrícolas permanecem dependentes de muitos serviços dos ecossistemas. Portanto, a biodiversidade caracteriza-se por ser um insumo essencial para a produção agrícola, tanto assim que danos causados à ela podem causar importantes prejuízos para a própria agricultura. 


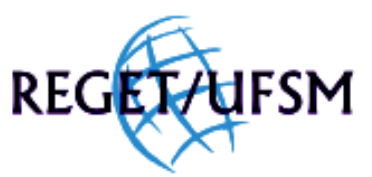

Araújo et al., v(6), no 6, p. 1203 - 1210, 2012.

1208

Rev. Elet. em Gestão, Educação e Tecnologia Ambiental

(e-ISSN: 2236-1170)

Entretanto, o autor afirma ainda que a expansão e intensificação da agricultura tem exercido papel importante na redução da biodiversidade, através da supressão dos habitats naturais expansão de áreas de produção.

Fatores como desmatamentos, queimadas, destruição de habitats, fragmentação de florestas, assoreamento de rios e lagos, aterramento de banhados, uso indevido de áreas de conservação, exploração demasiada da fauna e da flora, poluição de ambientes naturais, entre muitos outros, são os responsáveis pela redução da biodiversidade do nosso país.

Os efeitos destas perdas prejudicam não só os serviços prestados pela biodiversidade, mas também a produção destes sistemas agrícolas (Varella e Rocha et al, 1999).

Neste sentido, o estabelecimento de unidades de conservação e corredores biológicos naturais são imprescindíveis para a manutenção da biodiversidade e devem ser protegidos para existam áreas de continuidade entre os fragmentos de maciços florestais. (RICHTER, 1998)

Assim, de acordo com Fonseca (1997), as unidades de conservação têm o objetivo de conservar a biodiversidade e aumentar o nível de conhecimento sobre as comunidades florísticas e faunísticas nelas representadas, em particular a porção ameaçada em função do impacto humano direto e indireto.

Em países de altíssima riqueza biológica, como o Brasil, os percentuais alocados em forma de áreas protegidas é insuficiente para assegurar a proteção da biodiversidade (Richter, 1998)

Queiróz et al., (1997) atribui a fragilidade do sistema de unidades de conservação do país à falta de capacidade dos órgãos de governo em proporcionar os instrumentos adequados ao seu manejo e proteção.

Cumpre salientar, como relata Fonseca (1997), que não só a diversidade regional pode decrescer em função da degradação de ecossistemas naturais, mas também as comunidades aparentemente em bom estado, protegidas na forma de unidades de conservação, irão experimentar um processo de erosão de diversidade biológica até mesmo na ausência de impactos diretos subsequentes.

A conservação da biodiversidade não significa preservá-la de forma intocada, pois existem de estratégias de conservação que envolvem também o uso racional dos recursos naturais e garantem que os processos que geram e mantêm a biodiversidade permaneçam junto aos benefícios diretos de sua exploração (Bensusan, 2006). 


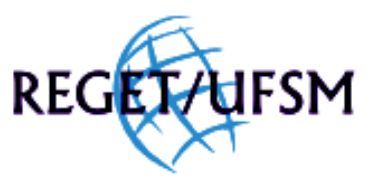

Richter (1998) lembra ainda que a falta de consciência ecológica promove o desinteresse e desrespeito dos cidadãos em relação à natureza. Portanto, necessária a criação de mecanismos que levem à população o conhecimento das espécies, suas inter-relações e a importância das mesmas para a manutenção dos ecossistemas.

\section{CONCLUSÃO}

Nesse sentido, programas de educação ambiental são de fundamental importância na sensibilização da população, pois permitem que os indivíduos conscientizem-se em relação à necessidade de se preservar o meio ambiente, a partir de conhecimentos e valores éticos e morais, orientados para a sustentabilidade, utilizando-se para isso, o esclarecimento de comunidades e populações sobre a importância ambiental, social, econômica e cultural da biodiversidade.

É visto que o meio ambiente sofreu e está sofrendo graves conseqüências em função do desenvolvimento. Não se pode negar que se desenvolver é preciso, no entanto o que se discuti é a maneira predatória que isso ocorreu e que ainda vem ocorrendo. $\mathrm{O}$ debate para que se consiga reverter, ou amenizar os impasses gerados por esse desenvolvimento incontrolável vai muito além. É considerável que a crise ambiental está intrinsecamente ligada aos problemas sociais e esses decorrem do paradigma da sociedade moderna e da época pós-moderna em que vivemos.

\section{REFERÊNCIAS}

BENSUSAN, N. Biodiversidade: é para comer, vestir ou para passar no cabelo? : para mudar o mundo! Editora Peirópolis, 2006; 418 p.

Brasil, MMA. A Convenção sobre Diversidade Biológica - CDB, Cópia do Decreto Legislativo no 2, de 5 de junho de 1992. MMA. Brasília, 2002, p.30 


\section{REGETUFSM} Rev. Elet. em Gestão, Educação e Tecnologia Ambiental

(e-ISSN: 2236-1170)

FONSECA, G. A. B.; PINTO, L. P. S.;RYLANDS, A. B.; BIODIVERSIDADE E UNIDADES DE CONSERVAÇÃO. Conservation International do Brasil, 1997;

FOUCAULT, M. "Os recursos para o bom adestramento". Vigiar e punir: nascimento da prisão. 29a ed. Tradução de Raquel Ramalhete. Petrópolis, RJ: Vozes, 2004, p. 153-72

INSTITUTO BRASILEIRO DE GEOGRAFIA E ESTATÍSTICA. Eco 92 Disponível em: <http://ibge.gov.br/ibgeteen/datas/ecologia/eco92.html>. Acesso em: 5 dez. 2011.

RICHTER, M.; Conservação da biodiversidade \& desenvolvimento sustentável de São Francisco de Paula: um plano de ação preliminar. EDIPUCRS, 1998; 108 p.

SOARES, H.; I $n$ t e r d i s c i p l i n a ri d a d e. Texto publicado no Jornal A razão em 01/07/1999.

V ARELLA, M. D.; ROCHA, F. A. N. G.; Biossegurança e biodiversidade: contexto científico e regulamentar. Editora del Rey, 1999; 301 p.

VEIGA-NETO, A. Currículo e exclusão social. In: CANEN, A. MOREIRA, A. F. (Orgs.). Ênfases e omissões no currículo. Campinas/SP: Papirus, 2001. 